\title{
Strategies for Fractions on RtI Instructional Framework: The Effect on Learning Disabled Middle Grades Students' Performance
}

\author{
Panagiotis G. Papadimitriou, Sotiria Tzivinikou* (]) \\ Department of Special Education, University of Thessaly, Volos, Greece \\ Email: *sotitzivi@uth.gr
}

How to cite this paper: Papadimitriou, P. G., \& Tzivinikou, S. (2020). Strategies for Fractions on RtI Instructional Framework: The Effect on Learning Disabled Middle Grades Students' Performance. Psychology, 11, 692-703.

https://doi.org/10.4236/psych.2020.115047

Received: March 6, 2020

Accepted: May 18, 2020

Published: May 21, 2020

Copyright $\odot 2020$ by author(s) and Scientific Research Publishing Inc.

This work is licensed under the Creative Commons Attribution-NonCommercial International License (CC BY-NC 4.0).

http://creativecommons.org/licenses/by-nc/4.0/

\begin{abstract}
Teaching fractions, and the concepts around them, has been proven to be a challenging task as multiple skills are required. This study examines the effectiveness of an intervention based on the "Response-to-Instruction" (RtI) model to students with math learning difficulties. The intervention was designed for teaching fractions, including both conceptual and procedural knowledge, to thirteen students with learning difficulties, attending mainstream middle schools in Greece. Its design was based on explicit instruction and on the Concrete-Representational-Abstract (CRA) strategy. The aim of this study is to evaluate the impact of the intervention and students' intra-individual improvement, using parametric statistical t-test of dependent samples. We used Single Case Design (SCD) with multiple baseline measures type A-B as an experimental design. We found a significant positive effect on students' performance in fractions and reliable data to monitor each student's responsiveness. The results of the present study converge with the findings in the literature that argue that explicit instruction and CRA strategy have a significant positive effect on developing mastery about fraction concepts in students with learning difficulties.
\end{abstract}

\section{Keywords}

RtI, Mathematics, Fractions, CRA Strategy, Explicit Instruction, Learning Disabilities

\section{Introduction}

Research findings reveal that the concept of fractions features particular difficulties and misunderstandings (Ennis \& Losinski, 2019; Gelman \& Williams, 1998; 
Siegler, Thompson, \& Schneider, 2011; Van de Walle, Karp \& Bay-Williams, 2013). These difficulties are due to the fact that rational numbers do not result from a natural thought process (as natural numbers do) and that mental schemas with which students understand natural numbers negatively affect the acquisition of fraction concepts (Koleza, 2000). Moreover, the learning process becomes even more challenging for students who struggle with mathematics (NMAP, 2008; Tzivinikou, 2018), as they face further difficulties in abstract thinking, visual and auditory perception, subtle mobility and spatial organization, receptive and expressive speech and memory (Agaliotis, 2011). The framework of the present study is the Response-to-Instruction (RtI) model. According to this model, students are selected for further instructional support based on findings from the universal screening process at the beginning of the school year (Gersten et al., 2009). The present study examines how effective the explicit and systematic instruction might be, when combined with the CRA strategy, in a math intervention about fraction concepts and operations.

\section{Response to Instruction (RtI)}

RtI primary goal is to prevent learning disabilities using early identification of difficulties, applying a three-tiered appropriate and effective instruction (Forbringer \& Fuchs, 2014). The use of the term learning disabilities refers to students who are currently diagnosed as having learning disabilities, as well as students at risk for mathematics failure (Fuchs et al., 2010; Gersten, Jordan, \& Flojo, 2005).

The first step of the implementation phase begins with a universal screening process to identify students at risk for learning disabilities or academic failure. Universal screening assessments are typically brief; they are conducted with all students at a grade level and provide valuable data about their performance. Gersten et al. (2011) claim that "without universal screening, there is no RtI". The RtI model includes a continuous and multitier process that focuses on how students with learning difficulties respond to high-quality scientific intervention based on research findings. The structure of the RtI is based on a three-tier intervention system. According to Forbringer and Fuchs (2014), the $1^{\text {st }}$ tier represents the general classroom settings, where a high-quality instruction is delivered according to state standards. The $1^{\text {st }}$ tier identifies students who have learning difficulties or those who are at risk for learning difficulties (Forbringer \& Fuchs, 2014). The $2^{\text {nd }}$ tier focuses on students (about 15\% - 20\%) who did not reach the expected learning level at the $1^{\text {st }}$ tier. Teaching is conducted in small groups of students (namely, 3 - 8 students) for a certain period of time by special education teachers. The overall duration of an intervention depends on the students' responsiveness and progress (Gersten et al., 2009). If difficulties persist, interventions can be adjusted or students can be referred to the next tier of support. The $3^{\text {rd }}$ tier is for students who need more intensive assistance, which may include individual mathematics instruction or a referral for special education 
evaluation. Data originating from the implementation of the RtI model in the U.S.A. in 2010 showed a large increase in schools adopting the RtI model, with $61.2 \%$ applying or being at the process of applying it. The application of the RtI model is more common in primary education rather than in secondary education and even less common in the field of mathematics, highlighting an interesting field for further research on which the current study is attempting to contribute (Forbringer \& Fuchs, 2014; Gersten et al., 2009).

\section{Explicit Instruction and CRA Sequence}

Gersten, Beckmann, Clarke, Foegen, Marsh, Star, and Witzel (2009) have gathered a set of research-based effective instructions for teaching math to students in the $2^{\text {nd }}$ tier of RtI, emphasizing the use of two key instructions, CRA sequence and explicit instruction. Archer and Hughes (2011) note that explicit instruction includes a series of support mechanisms and scaffolds. The authors state that the learning process should be guided and supported in order to master a new skill. The process contains clear statements and explanations of the instructional goals, learning expectations, step-by-step demonstrations, adequate range of examples and frequent feedback. Sixteen design guidelines and instructional practices are proposed for the implementation of direct and explicit teaching (Archer \& Hughes, 2011). Instruction is highly organized in an analytical format and involves teacher led explanations of concepts and strategies that help students build the new concepts on the prior knowledge.

The CRA sequence is a strategy starting from models of everyday objects, continuing with representational models and resulting in the typical symbolic form of mathematical concepts (Tzivinikou, 2018). Math manipulatives, number lines, graphs and simple drawings of concrete objects help students understand and associate math concepts with abstract mathematical symbols. Expressing mathematical ideas with visual representations and converting visual representations into symbols facilitate understanding which is crucial for reaching success in maths (Gersten et al., 2009). In the case of the fractional unit, the transition from a concrete phase to a representational phase and finally to an abstract phase is the one shown in the Figure 1. Within the concrete phase, students approach the concept of fractional unit with manipulative materials, such as pizza models, transparent measuring cups, chocolates, wooden color cubes or wooden bars. Within the representational stage, teachers utilize drawings representations and empower students to draw shapes on their own for problem solving (e.g. cycles, rectangles, sets and equally divided lines). Finally, within the abstract stage, students utilize mathematical symbols to solve problems.

Explicit instruction and CRA sequence are key pillars of applying the RtI model in mathematics (Gersten et al., 2009). The international literature reveals several important findings on the effectiveness of explicit instruction and the CRA sequence in mathematics for students with learning difficulties (Bouck \& Park, 2018; Forbringer \& Fuchs, 2014; Gersten et al., 2009; NMAP, 2008; Witzel, 


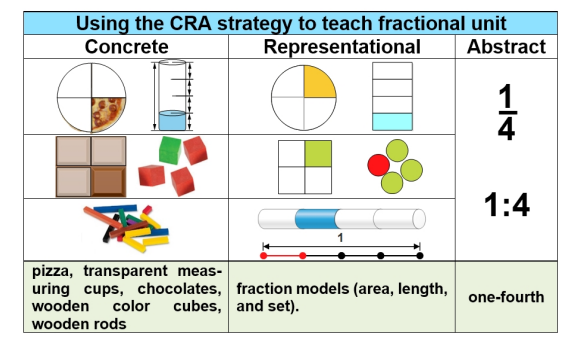

Figure 1. The three phases of CRA.

Riccomini, \& Schneider, 2008). Misquitta's review (2011) for interventions in fraction concepts, Gersten's et al. (2009) meta-analysis for students who struggle with mathematics and the National Mathematics Advisory Panel of USA relevant directives (NMAP, 2008) are of great importance. Findings from these studies establish the value of instructional approaches in teaching a variety of mathematical concepts, procedures and skills. Findings further confirm the effectiveness of such approaches in the learning performance and academic growth of students with learning disabilities or at risk for math failure. At this point, it is important to mention that the majority of these studies have been conducted in countries other than Greece with different educational systems. However, even in Greece, relevant studies were carried out based on an inclusive model differing substantially from the RtI model. The current study embracing the RtI approach endeavored to adjust it, taking into consideration the special features of the Greek school framework.

\section{Fractions across the Greek Mathematics Curriculum}

Fractions play an important role in mathematics education. Internationally, formal fraction instruction begins in the 3rd grade of elementary school and constitutes the prerequisite knowledge for the transition from the concept of the whole to the concept of the part (Van De Walle et al., 2013). It includes equal sharing problems, quantities partition and fractional concepts which are utilized in life aptitudes.

In the Greek educational system, introduction to fraction concepts starts at the 3rd grade of elementary school. Teaching begins with fractional units (using areas, lengths and sets models), continues with the concept of equivalence in fractions, basic operations with fractions and concludes with the relation between decimal fractions and decimal numbers as alternative forms of the same quantities. There is also focus on the relationship between fractions and decimals and how to convert a rational number from one form to another. Fraction instruction is typically completed at the end of elementary school, where students are expected to be able to label fractions, create, compare and order fractions with same or different denominators, convert unlike fractions into like fractions, identify and create equivalent fractions, simplify fractions, solve simple fractional problems, use the reduction method in the fractional unit and handle simple representations combining fractions and decimal numbers (Pe- 
dagogical Institute, 2003). Fractions are then repeated in the $1^{\text {st }}$ grade of middle school only for 10 hours in total as recommended in the national instructional guides (Ministry of Education and Religious Affairs, 2019). However, understanding fractions and concomitantly understanding rational numbers is a crucial issue in the transition from arithmetic to algebra and in addressing effectively their difficulties (NMAP, 2008).

\section{Research Design}

\subsection{Method}

The aim of this study is to evaluate the effectiveness of the $2^{\text {nd }}$ tier of the intervention in ameliorating understanding and calculating with fractions. The school that participated in this study was selected by using a typical case sampling approach. In this approach, the sample is not representative in the sense of probability sampling, but it is illustrative of other similar samples, so as not to be a specific or divergent case study (Etikan, Musa \& Alkassim, 2016; Mertens, 2015). The experimental design chosen was that of Single Case Design (SCD) with multiple baseline measures type A-B (pre-post). This design aims at exploring the impact of the independent variable in a small number of subjects (Kazdin, 2011). SCD is developed to essentially document in more detail three things: 1) if the independent variable has an observable and important impact, 2) if the observed change in the dependent variable is a result of the application of the independent variable and 3) if this change is generalizable across different settings and targets (Riley-Tillman \& Burns, 2009). The A-B type of SCD is the basic design to evaluate intervention effectiveness. This design compares intervention effects across students where the dependent variable (in this case "mathematical ability in fractions") was measured twice, once at the beginning and once at the end of the intervention. The multiple-baseline (MB) in this study refers to concurrent assessment (Concurrent multiple baseline design, CMBL) of all participants (students). This concurrency positively contributes in the internal validity of the research as it reduces history effects (Carr, 2005). MB design popularity is due to the fact that it does not require withdrawal of the independent variable, which may not be possible or may raise ethical problems.

\subsection{Participants}

Thirteen students in the first grade of a public middle school ( 5 boys and 8 girls) with typical demographics, situated in a Greek urban district, participated in this study $(\mathrm{N}=13)$. The Paps screening tool (Papadimitriou, Stathopoulou, \& Tzivinikou, 2015) was used to detect learning difficulties in mathematics. The Paps tool is a researcher-devised measuring tool for Middle Mathematics. We divided the group into two subgroups: the first subgroup included five students and the second eight students. Five of the students were diagnosed with special educational needs (learning disabilities) by a Centre of Diagnosis, Assessment and Support, as it is required by Greek Law. All of the students had low performance in math ability. Table 1 shows information on performance on mathematics, 
Table 1. Participants' descriptives.

\begin{tabular}{|c|c|c|c|c|}
\hline \multicolumn{5}{|c|}{ Participants Descriptives } \\
\hline Student & Gender & Paps Score & * & ** \\
\hline S1 & Male & 12 & 71 & $\checkmark$ \\
\hline S2 & Female & 9 & 71 & \\
\hline S3 & Female & 6 & 77 & \\
\hline S4 & Female & 8 & 77 & \\
\hline S5 & Male & 5 & 73 & $\checkmark$ \\
\hline S6 & Male & 8 & 79 & \\
\hline S7 & Female & 10 & 79 & \\
\hline S8 & Male & 11 & 73 & \\
\hline S9 & Female & 5 & 77 & \\
\hline S10 & Female & 12 & 77 & \\
\hline S11 & Female & 4 & 69 & $\checkmark$ \\
\hline S12 & Female & 5 & 67 & $\checkmark$ \\
\hline S13 & Male & 10 & 81 & $\checkmark$ \\
\hline
\end{tabular}

Paps: Screening tool to assessing mathematical ability for middle school students. ${ }^{*}$ Mathematical Proficiency Criterion (Barbas et al., 2008); ${ }^{* *}$ Diagnosis of a learning disability after assessment at a Centre of Diagnosis, Assessment and Support.

measured with the Paps tool, scoring in the Mathematical Proficiency Criterion (Barbas et al., 2008) and shows whether the participant student has been diagnosed with a learning disability after assessment at a Centre of Diagnosis, Assessment and Support.

All students had a low level of mathematical proficiency in the universal screening. They were in the 20th percentile that comprises the cut-off criterion (as defined in Paps) for eligibility of students who need further instructional support in tier 2. Specifically, the value range was [5-12] and the mean value was 8 in a rating scale 0 - 40 (column Paps Score, Mean 20 and SD 8). Similarly, a low scoring (mean score 75) appeared in students' performance in the "Mathematical Proficiency Criterion tool" which scores follow a normal distribution with a mean of 100 and standard deviation of 15 (Barbas et al., 2008). Five out of the thirteen participants $\mathrm{h}$ ad a diagnosis of a learning disability after assessment at a public Centre of Diagnosis.

\subsection{Intervention Procedure}

The intervention on fractions that was implemented has both similarities and differences with formal instruction conducted in the $1^{\text {st }}$ tier. Firstly, our teaching approach was explicit and systematic and secondly, the CRA strategy was constantly used.

For the initial assessment of students' mathematical ability in fractions and for monitoring their progress, we developed tools based on the content of the cur- 
riculum used in elementary and first grade of middle school. The first tool assessed the concept of rational numbers, while the second referred to fractional operations. Each tool contained eight specific tasks. In particular, the tool for the concept of rational numbers included: 1) a geometric representation of fractions which were greater or less than a whole, with the use of surface models (identification), 2) a geometric representation of fractions, which were greater or less than a whole, with the use of length models (identification), 3) comparison of fractions, 4) a simple word problem with or without visual aids (pictures or representations); 5) comparison of decimals, and 6) conversion of a fraction to a decimal number.

The tool for assessing fraction operations comprised two tasks for each operation in order to include the most representative cases. Moreover, a detailed description for each task was provided at the end of the tool in order to be able to form new but identical forms of exercises. The content validity was achieved through the correlation of the mathematical content of the assessing tool with the curriculum in elementary school. Both the math curriculum of the Hellenic Ministry of Education (Pedagogical Institute, 2003) and students' and teachers' textbooks from all grades of elementary and middle school were used as research and documentation materials. Furthermore, we addressed the aforementioned tools to ten mathematicians with masters' degree in education and the content validity ratio was found to be the maximum possible, equal to 1 . All assessments were made by using these tools.

The intervention duration was 15 instructional hours (45 minutes/hour) and involved the concept of fraction, equivalence of fractions, comparison and fractional operations. The intervention was intensified by providing explicit and systematic instruction, continuous use of the CRA strategy and increased time for student feedback. This intensified intervention consisted of two components: conceptual understanding and procedural skills. In order to introduce the concept of fraction, the instructional approach adopted the following sequence: area models, length models and set models (Van De Walle et al., 2013). Visual representations, such as number lines, arrays and strip diagrams were used.

Students received math instruction which focused on fraction vocabulary, solving simple word problems, verbalization of thought processes, guided practice and frequent cumulative review. Presentation of goals and learning expectations, continuous practice, repetition and feedback to students through monitoring progress data played an important role. The lack of appropriate educational material for the RtI model implementation was a crucial obstacle (Spectrum K12 School Solutions, 2010), which was handled by developing printed and digital material and using the educational package of A-Learning series (Tzivinikou, 2018).

Each session for the intervention begins similarly, with the teacher providing a graphic organizer, which involves the teacher demonstrating what the students will be learning, activating prior knowledge and stating expectations. Table 2 provides a 45 -min intervention plan aiming to the concept of fractions division. 
Table 2. A 45-min intervention plan.

\begin{tabular}{ccc}
\hline Fractions & Basic fractional concepts & Operations $\checkmark$ \\
\hline & Division of fractions (1) \\
Understanding division of fractions (1.a)
\end{tabular}

Lesson Abstract: Before students begin using algorithms for the division of fractions, they should have a conceptual understanding.

Tier 2

\author{
Overall goal: \\ Lesson Goals:

\section{Learning outcomes} \\ Instructional \\ Resources/Materials: \\ Explicit instruction
(teaching model)
}

Critical content: concepts (division, Partitioning, equal shares), vocabulary terms (fraction language e.g. numerator, denominator), skills (partitioning with Area Models, understanding equivalent fractions). Statement of the lesson's goals and expectations: division of fractions/learning outcomes. Introduced lesson with activating prior skills and knowledge (warm-up): starter activities with division word problems that include only whole numbers (both type: partitive and measurement). [ 28 euros to buy 7 tickets. How much does each ticket cost? / A serving is 3 cookies. How many servings can I make from 36 cookies?]
Students who are at risk for mathematics failure

\section{Intervention plan}

The mastery of fractions so as to be able to meet adequately the requirements in the general education classroom (tier 1)

$\Rightarrow$ Division of a fraction by a whole number

$\Rightarrow$ Division of a fraction by a fraction

$\Rightarrow \quad$ Using area models to demonstrate a simple division of fractions (e.g. 1/2:2, 2:1/4)

$\Rightarrow$ Describe and explain how they work

$\Rightarrow$ Solving simple problems.

transparent measuring cups (or transparent plastic water bottles $3 / 4,1,3 / 2 \& 2$ liters), rectangles area fraction models

CRA (instructional strategy)
After the introduction of the lesson, the teacher starts applying the first phase of CRA strategy. Teacher using 1-liter bottle full of water asks students to empty their contents equally into two empty bottles (as shown in the figure below). Provide interaction via the use of appropriate questioning, immediate affirmative and corrective feedback. Then teacher demonstrate the activity and clarify the decision-making processes needed to complete the procedure in order to show students a model of proficient performance. As students share thinking that indicates they are beginning to understand the mathematical concept, there can be transit to representational phase. Finally, the mathematical symbols are used to represent the operation of division.

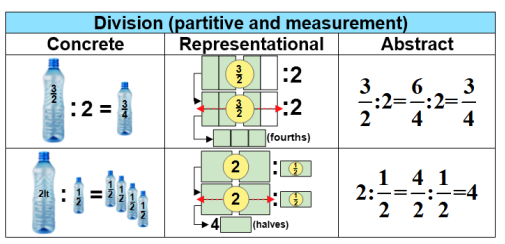

Guided and supported practice

"I have showed you how I solve two problems, I am going to have you try two yourself", "show two different ways to model the solution for each problem". [e.g. If you have 3 liters of milk, how many bottles holding 3 quarts each can you fill?]

Independent and cumulative practice (homework)

Students practice the skill or solve the problems without any assistance or prompts from the teacher

\section{Results}

The parametric statistical t-test of dependent samples was used to evaluate the effectiveness of the intervention. In this way the efficacy of intervention in students' progress was examined, comparing the difference in their performance 
before and after intervention. Separate tests were performed for each evaluation criteria category for all 13 students. The rating scale for each criterion was [0 8]. Each test was performed assuming that the null hypothesis $\left(\mathrm{H}_{\mathrm{o}}\right)$ is that the mean score of the students after intervention ( $\mu$-post) was equal to the mean score before intervention ( $\mu$-pre) versus the alternative hypothesis $\left(\mathrm{H}_{1}\right)$ that this did not hold. The results revealed that the test on the concept of explicit numbers showed $\mathrm{p}=0.056>0.05=\mathrm{a}$ and marginally the null hypothesis on the equality of the mean values was not rejected. However, the difference is large ( $\mu$-post $=4.462 \& \mu$-pre $=0.077)$ and qualitative features on the analysis of findings indicative a very positive effect of the intervention for 4 out of 13 students. On the test for fractions the null hypothesis was rejected on all the usual levels of statistical significance, since the p-value was found to be $0.001<0.5=\alpha$. It was also found that the mean value for the group of 13 students before intervention was 0.077 , while after intervention it was 4.462 . Finally, the $95 \%$ confidence interval for the mean difference in the scores of the 13 students ( $\mu$-post) - ( $\mu$-pre) is $(2.313,6.457)$, indicating the positive effect of the teaching intervention.

The findings were positive regarding the functional relation between the use of the explicit instruction and CRA strategy and revealed positive changes in students' mathematical scores from pretest to posttest. Further findings emerged from the examination of the individual performance differences for each task of the evaluation criteria overall (pre-post). By dividing these differences into three categories, based on the magnitude of the change (Figure 2), it was found that students' performance increased to a larger extend in projects that required more procedural knowledge than conceptual knowledge.

\section{Discussion}

The main purpose of the study was to examine the effectiveness of fraction instruction based on explicit instruction and CRA sequence addressed to students with learning difficulties within an RtI school framework. The students who participated in the research made progress in math assessment performance related to fractions. In the fraction concepts, there was a mean value from 1.615 to 3 in performance and from 0.077 to 4.462 in operations after the intervention. These results converge with the findings of Flores, Hinton, \& Taylor (2018), Forbringer
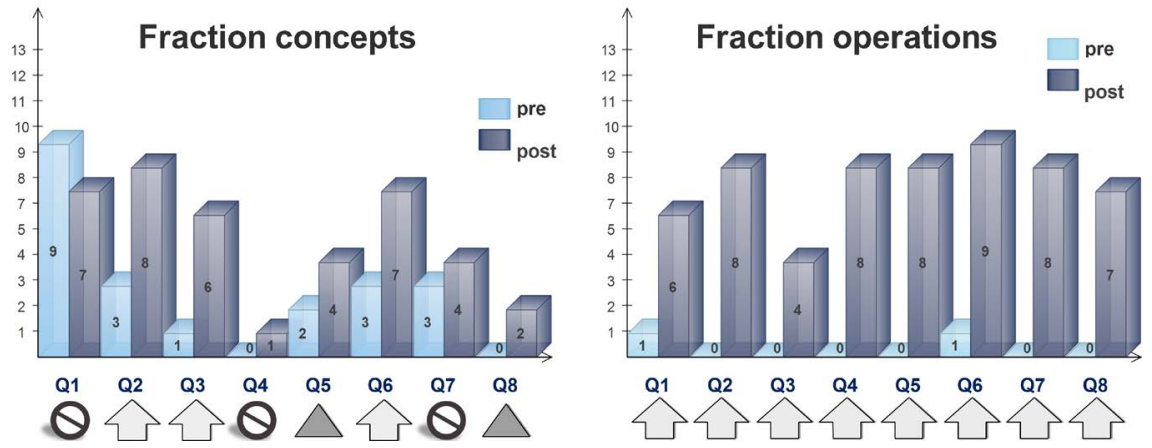

Figure 2. Intervention effects on fraction concepts and operations. 
\& Fuchs. (2014), Gersten et al., (2009) and Misquitta (2011), who stressed that systematic and explicit teaching in combination with CRA sequence have a positive impact on the acquisition of mathematical concepts for students with learning difficulties. However, cumulative cognitive deficits of students in relation to the expected learning outcomes (after the end of elementary school) and the hierarchical structure of mathematics pose obstacles that are difficult to handle. Intervention even at this supportive tier ( $2^{\text {nd }}$ tier) does not meet the needs of all students, and therefore, tackling difficulties requires further support ( $3^{\text {rd }}$ tier) for these students.

The positive effect in procedural knowledge has shown that despite the presence of general learning difficulties, it is more accessible than conceptual knowledge. Thus, in the task requiring the solution of a simple word problem, students' performance increased from $23 \%$, prior to the intervention, to $46 \%$, after the intervention. Whereas, in three fractions addition with unlike denominators, students' performance significantly advanced, from zero increased to $46 \%$. A rather significant element which is interrelated with the Rtl application is the exploitation of the assessment data deriving from each student's progress monitoring in a way that demonstrates the impact of the intervention. This gave us the opportunity to evaluate each student's responsiveness to intervention and based on the assessment data design more effective individualized instruction support.

The effectiveness of instructional interventions in small groups with methods such as $\mathrm{t}$-test is formulated using the arithmetic mean. It is a single number that describes the accumulation of values attributed to the variable under examination on one critical value. However, despite the un-doubted benefit of a concise and comprehensive description of the data, the value of the variable of such interventions is underestimated. Limitations exist in the attempt to generalize research findings across other students, time, and "similar" settings. Choosing the SCD experimental methodology applied in small groups of students, cannot lead sufficient generalized conclusions. On the other hand, the focus on small groups could be unique in a number of ways compared to collecting data from a larger number of students. It is this systematic replication of observed intervention effects that will increase external validity and is therefore the target of our broader RTI research.

Another issue we encountered when conducting the intervention was students' negative perceptions of using concrete manipulatives material. As Satsangi and colleagues mentioned (2016), the provision of learning helps to secondary students, such as concrete objects, can have a negative influence since students themselves think that the use of such objects distinguish them from their typical peers. We observed this negative concern from students' comments during the intervention, despite the benefits of CRA. Replacing the concrete objects with digital versions (virtual objects) is an option that merit further investigation. Concluding, CRA and explicit instruction capitalizes the tiered instructional processes of RTI. The implementation of the RtI model is a research evidence 
well accepted approach for addressing learning-oriented learning difficulties that may well be actualized within the Greek instructive system.

\section{Conflicts of Interest}

The authors declare no conflicts of interest.

\section{References}

Agaliotis, I. (2011). Teaching Mathematics in Special Education. Athens: Grigoris Publications. (In Greek)

Archer, A., \& Hughes, C. (2011). Explicit Instruction: Effective and Efficient Teaching. New York: Guilford Publications.

Barbas, C., Vermeoulen, F., Kioseoglou, G., \& Menexes, G. (2008). Psychometric Criterion of Mathematical Proficiency for Children and Adolescents. EPEAEK Project "Psychometric and Differential Evaluation in Children and Adolescents with Learning Disabilities". Thessaloniki. (In Greek)

Bouck, E. C., \& Park, J. (2018). A Systematic Review of the Literature on Mathematics Manipulatives to Support Students with Disabilities. Education and Treatment of Children, 41, 65-106. https://doi.org/10.1353/etc.2018.0003

Carr, J. E. (2005). Recommendations for Reporting Multiple-Baseline Designs across Participants. Behavioral Interventions, 20, 219-224. https://doi.org/10.1002/bin.191

Ennis, R. P., \& Losinski, M. (2019). Interventions to Improve Fraction Skills for Students with Disabilities: A Meta-Analysis. Exceptional Children, 85, 367-386. https://doi.org/10.1177/0014402918817504

Etikan, I., Musa, S., \& Alkassim, R. (2016). Comparison of Convenience Sampling and Purposive Sampling. American Journal of Theoretical and Applied Statistics, 5, 1-4. https://doi.org/10.11648/j.ajtas.20160501.11

Flores, M., Hinton, V., \& Taylor, J. (2018). CRA Fraction Intervention for Fifth-Grade Students Receiving Tier Two Interventions. Preventing School Failure: Alternative Education for Children and Youth, 62, 198-213. https://doi.org/10.1080/1045988X.2017.1414027

Forbringer, L., \& Fuchs, W. (2014). RtI in Math. New York: Routledge, Taylor \& Francis Group, LLC. https://doi.org/10.4324/9781315852270

Fuchs, L. S., Powell, S. R., Seethaler, P. M., Fuchs, D., Hamlett, C. L., Cirino, P. T., \& Fletcher, J. M. (2010). A Framework for Remediating Number Combination Deficits. Exceptional Children, 76, 135-156. https://doi.org/10.1177/001440291007600201

Gelman, R., \& Williams, E. M. (1998). Enabling Constraints for Cognitive Development and Learning: Domain Specificity and Epigenesis. In W. Damon, D. Kuhn, \& R. S. Siegler (Eds.), Handbook of Child Psychology: Vol. 2. Cognition, Perception, and Language (pp. 575-630). Hoboken, NJ: John Wiley \& Sons Inc.

Gersten, R., Beckmann, S., Clarke, B., Foegen, A., Marsh, L., Star, J. R., \& Witzel, B. (2009). Assisting Students Struggling with Mathematics: Response to Intervention (RtI) for Elementary and Middle Schools (NCEE 2009-4060). Washington DC: National Center for Education Evaluation and Regional Services, Institute of Education Sciences, U.S. Department of Education.

Gersten, R., Dimino, J., \& Haymond, K. (2011). Universal Screening for Students in Mathematics for the Primary Grades. The Emerging Research Base. In R. Gersten, \& R. Newman-Gonchar (Eds.), Understanding RTI in Mathematics. Proven Methods and Applications (pp. 17-33). Baltimore, MD: Paul H. Brookes Publishing CO. 
Gersten, R., Jordan, N. C., \& Flojo, J. R. (2005). Early Identification and Interventions for Students with Mathematics Disabilities, Journal of Learning Disabilities, 38, 293-304. https://doi.org/10.1177/00222194050380040301

Kazdin, A. E. (2011). Single-Case Research Designs (2nd ed.). New York: Oxford University Press.

Koleza, E. (2000). Cognitive and Didactic Approach to Early Mathematical Concepts. Athens: Leaders Books. (In Greek)

Mertens, D. (2015). Research and Evaluation in Education and Psychology: Integrating Diversity with Quantitative, Qualitative, and Mixed Methods (4th ed., p. 332). Thousand Oaks, CA: Sage Publications, Inc.

Ministry of Education and Religious Affairs (2019). Guidelines for Teaching Mathematics at the Middle School for the School Year 2019-2020. Athens: Ministry of Education and Religious Affairs. (In Greek)

Misquitta, R. (2011). A Review of the Literature: Fraction Instruction for Struggling Learners in Mathematics. Learning Disabilities Research \& Practice, 26, 109-119. https://doi.org/10.1111/j.1540-5826.2011.00330.x

National Mathematics Advisory Panel NMAP (2008). Foundations for Success: The Final Report of the National Mathematics Advisory Panel. Washington DC: U.S. Department of Education.

Papadimitriou, P., Stathopoulou, C., \& Tzivinikou, S. (2015). Response to Instruction and Intervention: Development of a Tool for the Screening of Mathematics Difficulties. In D. Desli, I. Papadopoulos, \& M. Tzekaki (Eds.), Mathematics with Discrimination and without Discrimination (pp. 157-166). Thessaloniki: ENEDIM. (In Greek)

Pedagogical Institute (2003). Single Cross Thematic Curriculum Framework and Compulsory Educational Curriculum. Athens: Government Gazette, Government Gazette, FEK 303B/13-03-2003, FEK 304B/13-03-2003. (In Greek)

Riley-Tillman, T., \& Burns, M. (2009). Evaluating Educational Interventions, Single-Case Design for Measuring Response to Intervention. New York: Guilford Publications.

Satsangi, R., Bouck, E. C., Taber-Doughty, T., Bofferding, L., \& Roberts, C. A. (2016). Comparing the Effectiveness of Virtual and Concrete Manipulatives to Learn Algebra for Secondary Students with Learning Disabilities. Learning Disability Quarterly, 39, 240-253. https://doi.org/10.1177/0731948716649754

Siegler, R. S., Thompson, C. A., \& Schneider, M. (2011). An Integrated Theory of Whole Number and Fractions Development. Cognitive Psychology, 62, 273-296.

https://doi.org/10.1016/j.cogpsych.2011.03.001

Spectrum K12 School Solutions (2010). Response to Intervention Adoption Survey 2010. http://sss.usf.edu/resources/presentations/2010/fasp summer inst2010/Resource SLD/ RTI/2010RTIAdoptionSurveyReport.pdf

Tzivinikou, S. (2018). Fractions and Decimals (Non-Negative Rational Numbers): Learning Disabilities and Mathematics. Volos: Readnet Publications. (In Greek)

Van de Walle, J., Karp, K., \& Bay-Williams, J. (2013). Elementary and Middle School Mathematics (6th ed.). Upper Saddle River, NJ: Pearson.

Witzel, B. S., Riccomini, P. J., \& Schneider, E. (2008). Implementing CRA with Secondary Students with Learning Disabilities in Mathematics. Intervention in School and Clinic, 43, 270-276. https://doi.org/10.1177/1053451208314734 